\title{
Auf Distanz gehen Über Angst und Reichtum
}

\author{
Erschienen in: ANGST + | FEAR + \\ Von: Armin Flender
}

Es sind Angehörige der begüterten Oberschicht von Florenz, die sich in Giovanni Boccaccios Decamerone die heiteren und amourösen Geschichten erzählen. Sie hatten es aus der Hölle von Florenz geschafft, wo 1348 die Pest wütete und nur die Flucht einen sicheren Ausweg bot. „In dieser Überzeugung verließen viele, Männer wie Frauen, ohne sich durch irgendeine Rücksicht halten zu lassen, allein auf die eigene Rettung bedacht, ihre Vaterstadt [...] und flüchteten auf ihren eigenen oder gar einen fremden Landsitz.“ Aber es konnten nur die wenigsten entkommen: „Die Lage der kleinen Leute [...] war noch viel elender, da sie entweder von der Hoffnung oder von der Armut in ihren Häusern zurückgehalten wurden, mit den Nachbarn verkehrten und daher täglich zu Tausenden erkrankten und bei dem vollständigen Mangel an Pflege und Hilfe rettungslos starben." ${ }^{1}$ Wer über keinen Besitz auf dem Land verfügte, hatte keine Chance, der Pest zu entgehen. Nicht nur, dass die Katastrophe vor allem in den Armenvierteln wütete: Aus der Katastrophe gingen das Patriziat und die Klasse der Reichen von Florenz gestärkt hervor. Der verbreitete Glaube, die von Gott gesandte Strafe richte unparteiisch und egalitär, war erschüttert, denn ganz offensichtlich wurden doch „die Reichen und Schönen entschieden bevorzugt, ganz wie Staat und Gesellschaft auf Erden."2

Die Angst vor Krankheit und Seuche, Naturkatastrophe und Krieg mag gleich verteilt sein, aber materieller Wohlstand gewährleistet unvergleichbar besseren Schutz vor zahlreichen Bedrohungen. Weit verbreitet scheint die Haltung von Wohlhabenden zu sein, sich untereinander zu vergemeinschaften und räumlich zu separieren. Eine Burg, einen Palast, ein Schloss oder eine Villa zu bauen, ist Ausdruck von Exklusivität und Macht, aber auch dem Gefühl von Unsicherheit und Angst geschuldet - bei Gefahr wird die Zugbrücke hochgezogen. Dieses Phänomen ist keineswegs neu. Reiche Römer lebten nicht in der antiken Metropole Rom mit einer Million Einwohnern, sondern in ausgedehnten Villen im Suburbium, einem Gebiet, das eine gute Tagesreise von Rom entfernt lag. Aufgrund der extrem hohen Bodenpreise war es ausschließlich sehr reichen Römern möglich, sich auf ihre Güter zurückzuziehen. Im Vergleich zum Moloch Rom mit beträchtlich plebejischem und politischem Gewaltpotential und geschätzt etwa 100 Bränden am Tag, herrschten auf dem Lande gesunde und sichere Lebensbedingungen, man konnte die Sommerfrische und die Schönheit der Natur genießen. Die Villen der Reichen waren exklusive Orte, an denen die römische Aristokratie dem Bildungserlebnis der griechischen Kultur frönen konnte. ${ }^{3}$ 

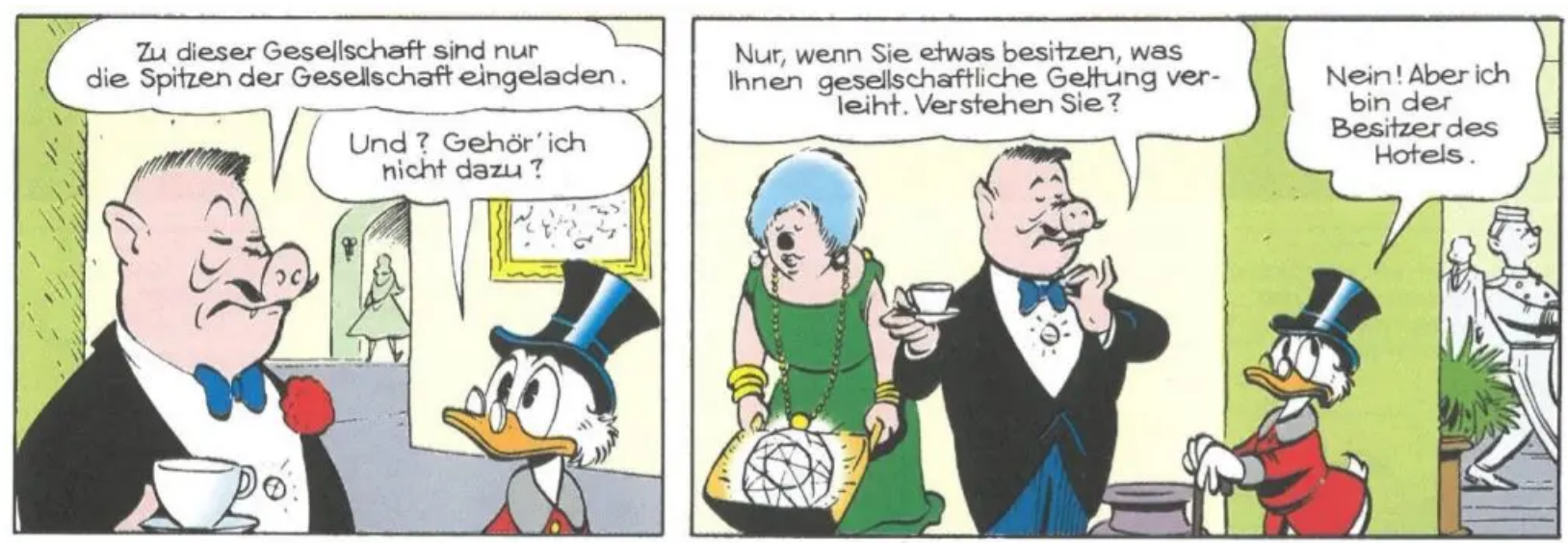

Abb. 1: Die Spitzen der Gesellschaft (1963), in: Barks Library Special - Onkel Dagobert, Bd. 24, Stuttgart 2002, S. 55.4

Der Gedanke räumlicher Separation trägt bis heute, wo Siedlungen und Apartmentanlagen mit Hilfe von Toren, Zäunen oder Mauern von der Umwelt abgesondert sind und mittels Kameras oder privater Security bewacht werden. Seit Ende der 1990er Jahre geraten diese gated communities als neue städtebauliche Phänomene verstärkt in den Blick der Öffentlichkeit. Strukturell handelt es sich auch hier um zumeist sehr teure Areale jenseits der Stadtzentren, wo exklusives Wohnen in Villen der Standard ist. ${ }^{5}$ Die Variante des durch Sicherheitszäune und Personal abgesicherten Bezirks ist in Deutschland, im Gegensatz zu Nord- und Südamerika und Teilen Osteuropas, noch nicht weit verbreitet. Auch wenn die eigene Scholle blickdicht abgegrenzt ist, herrschen hierzulande ansonsten noch mildere Formen der Abschottung. Ein anderer Straßenbelag, Hecken, Schranken, auch fehlende Sitzmöglichkeiten am Wegesrand vermitteln Besuchern, dass sie hier als Fremde unterwegs und unerwünscht sind. Der Schutzgedanke der Reichen ist gekoppelt an die Fremdzuschreibung des nicht dazugehörenden Besuchers, eine Herausforderung für das Selbstverständnis einer demokratischen Gesellschaft, in der der öffentliche Raum allen zur Verfügung stehen soll. 


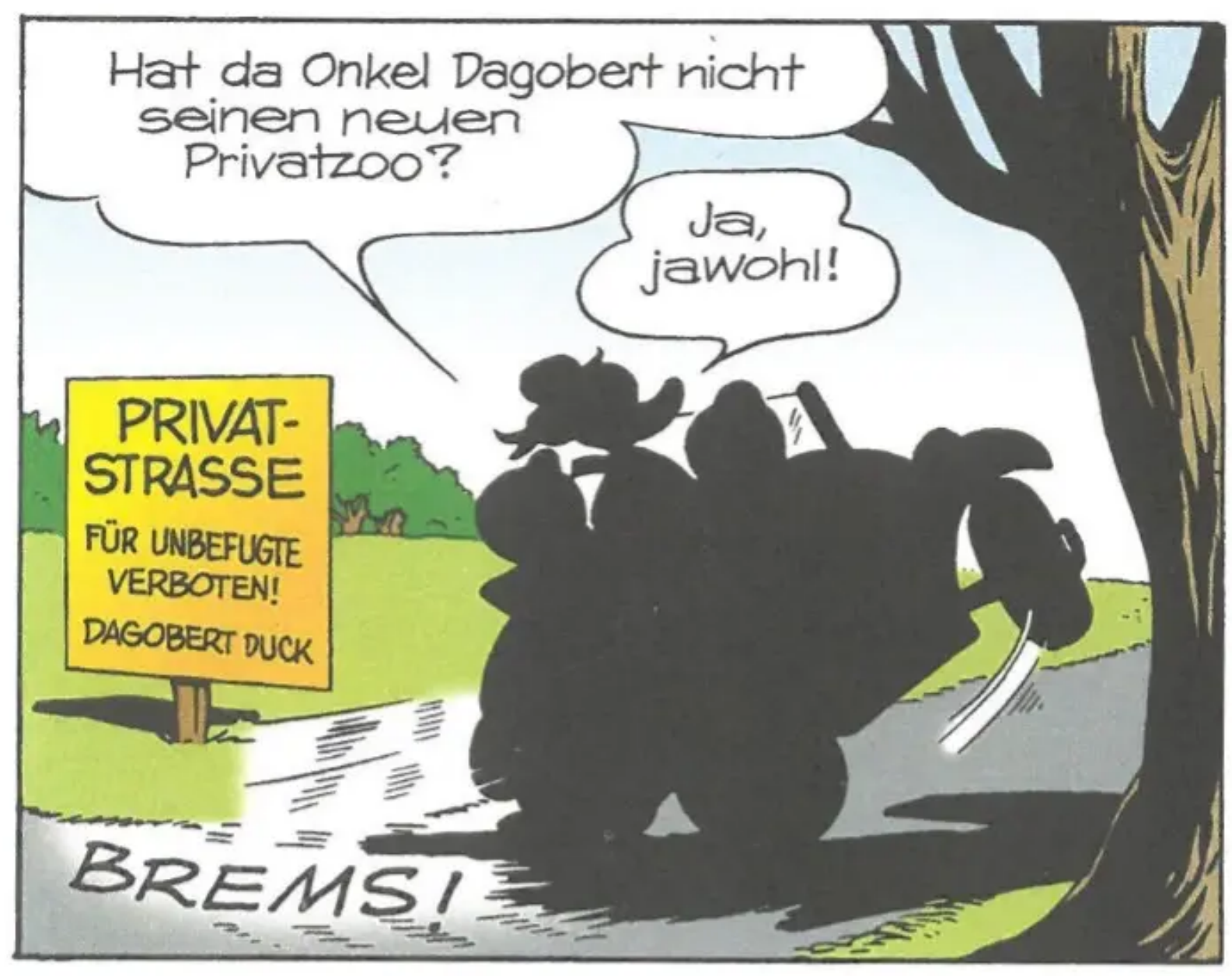

Abb. 2: Die Jagd auf das Einhorn (1950), in: Barks Library Special - Donald Duck, Bd. 13, Stuttgart 1996, S. 31.

In Arcadia, einem Grundstück in Potsdam mit 45 Wohnungen in sieben Villen, ist man weiter. Bei der Konzipierung war der Sicherheitsgedanke oberstes Prinzip. In den zu entrichtenden Nebenkosten bezahlen die Bewohner zwar auch für den Gärtner und den Blumengießservice, vor allem aber für den Sicherheitszaun und die Überwachungskameras. Das Betreten des Geländes ist nur noch mit einer Genehmigung möglich. ${ }^{6}$ Arcadia war die erste Siedlung, die in Deutschland unter dem Begriff der gated community vermarktet wurde. Das Projekt war zunächst umstritten, der Bauherr ging pleite und es dauerte Jahre, bis 2008 alle Wohnungen verkauft waren. Mittlerweile leben in Arcadia vor allem Betuchte und Betagte, die sich durch bewegungssensible Zäune von der Umwelt abschotten.

Mit Blick auf diese Entwicklung sah der Wohnsoziologe Tilman Harlander gated communities schon vor fast 10 Jahren als Zeichen für die freiwillige Segregation von Reichen in homogenen Quartieren. Slums, auf der anderen Seite, seien Ausdruck der strukturell erzwungenen sozialräumlichen Ausschließung der ohnehin sozial Exkludierten. Und während die einen die Gesellschaft und deren Solidarität nicht brauchen, wird den anderen diese Solidarität durch die Gesellschaft verweigert, eine Entwicklung, die immer weiter fortschreitet. ${ }^{7}$ Das sozial „empfehlenswerte 
Durcheinanderwohnen“, wie es der preußische Stadtplaner James Hobrecht mit Blick auf Berlin 1868 formuliert hatte, gerät immer mehr unter Druck und muss als Konzept immer wieder neu verteidigt werden.

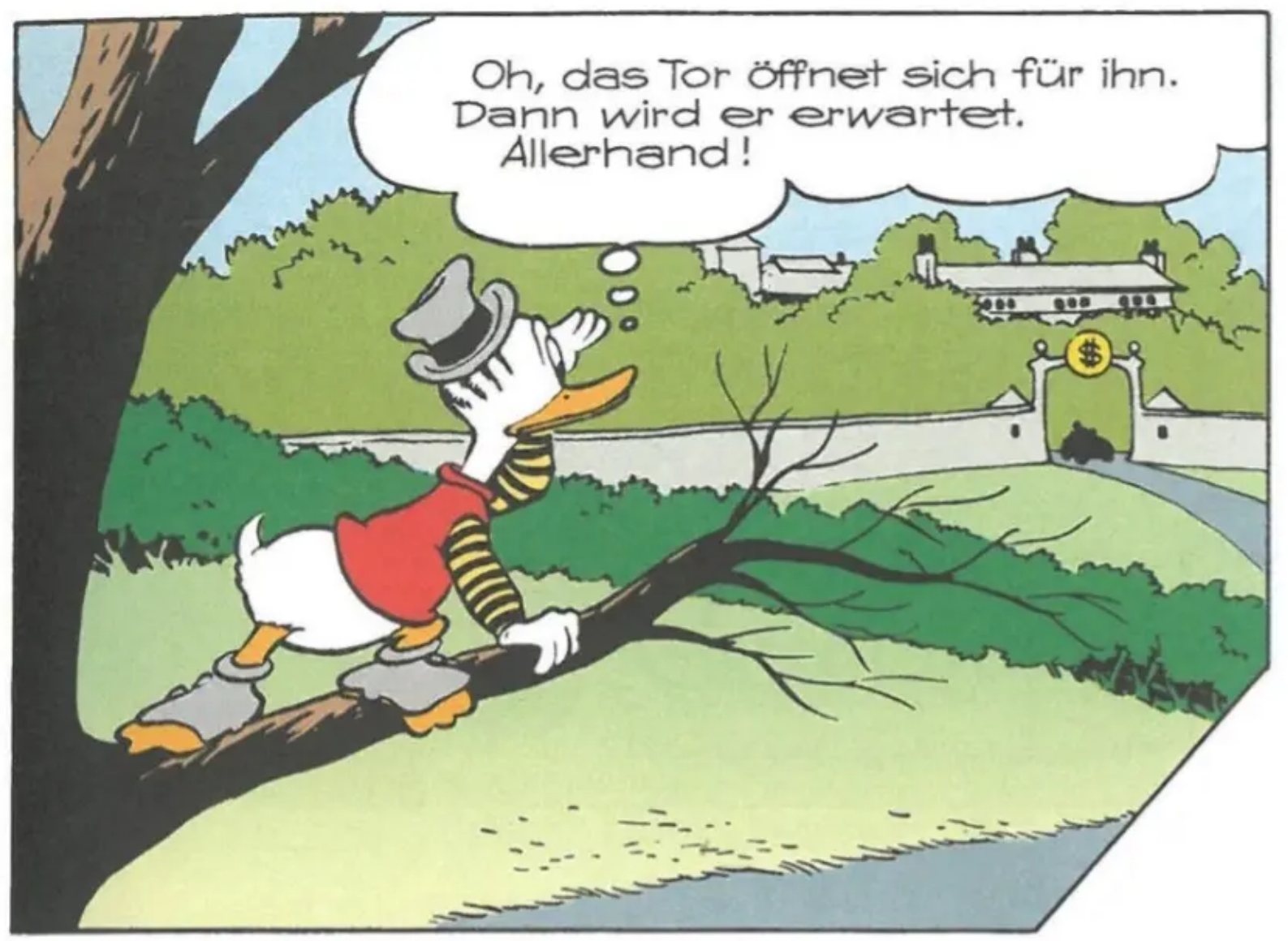

Abb. 3: Die Jagd auf das Einhorn (1950), in: Barks Library Special - Donald Duck, Bd. 13, Stuttgart 1996, S. 32.

Glaubt man den Meldungen, dann verlassen Tausende seit einigen Jahren Europa, besonders betroffen sind Rom, Athen und insbesondere Paris. Die Rede ist von Millionären: Allein 2015 verließen 10.000 von innen Frankreich und 2016 waren es erneut 7.000, die Paris den Rücken kehrten, was den „Stern“ zu der Aussage verleitete: "Die Nerze verlassen das sinkende Schiff“. 8 Frankreich und besonders seine Hauptstadt verzeichnet ein konstantes Minus an Millionären, das bis heute anhält. Die Verschwiegenheit dieser Klasse lässt über die Gründe für den Wegzug nur mutmaßen, aber mit Blick auf andere Länder mit nennenswerter Abwanderung von Reichtum wie Russland, die Türkei oder Brasilien, könnte Instabilität ein Grund sein. ${ }^{9}$ Offenbar fühlen sich Reiche auch in Frankreich nicht mehr sicher und verlassen das Land. 




Abb. 4: Hans Hackebeil (1959/60), in: Barks Library Special - Onkel Dagobert, Bd. 17, Stuttgart 2000, S. 34.

Ob die Tatsache, dass Reiche das Land verlassen, ein Indikator für gesellschaftliche Veränderungen ist, bleibt unklar. Aber im Gegensatz zu den meisten anderen sind nur Menschen mit entsprechenden finanziellen Mitteln überhaupt in der Lage, sich ein Domizil jenseits der Herkunftsgrenzen auszusuchen. Es sind nicht nur Städte wie Sydney, Melbourne oder Dubai: Auch Inseln werden zunehmend attraktiv für Reiche. Dieser Trend ist besonders seit der Corona-Pandemie zu beobachten. Die Pandemie erfasste 2020 alle Erdteile, nur noch down under und insbesondere Neuseeland blieben dank einer rigorosen Politik weitgehend vom Virus verschont. Damit wurde Neuseeland zu einem Sehnsuchtsort, zu einer Art Auenland für reiche Amerikaner, die den chaotischen Verhältnissen in den USA 2020 entfliehen wollten. Der Trend, sich in eine sozial und klimatisch bevorzugte Umgebung abzusetzen, ist nicht neu. Der britische Milliardär Richard Branson kaufte 1979 Necker Island in der Karibik, um dort besonders zahlungskräftigen Gästen exklusiven Tourismus anzubieten. Überschaubare Inseln, die weit entfernt von den bevölkerungsreichen Metropolregionen der Welt liegen, wurden seit dem Ausbruch der Corona-Epidemie zu begehrten Zufluchtsorten. Neben der Karibik zog es die Reichen auch zu den Atollen der Südsee wie Fidschi, das liquiden Besuchern und ihren Jachten in der Pandemie die Häfen öffnete - alle anderen durften nicht anlegen. 


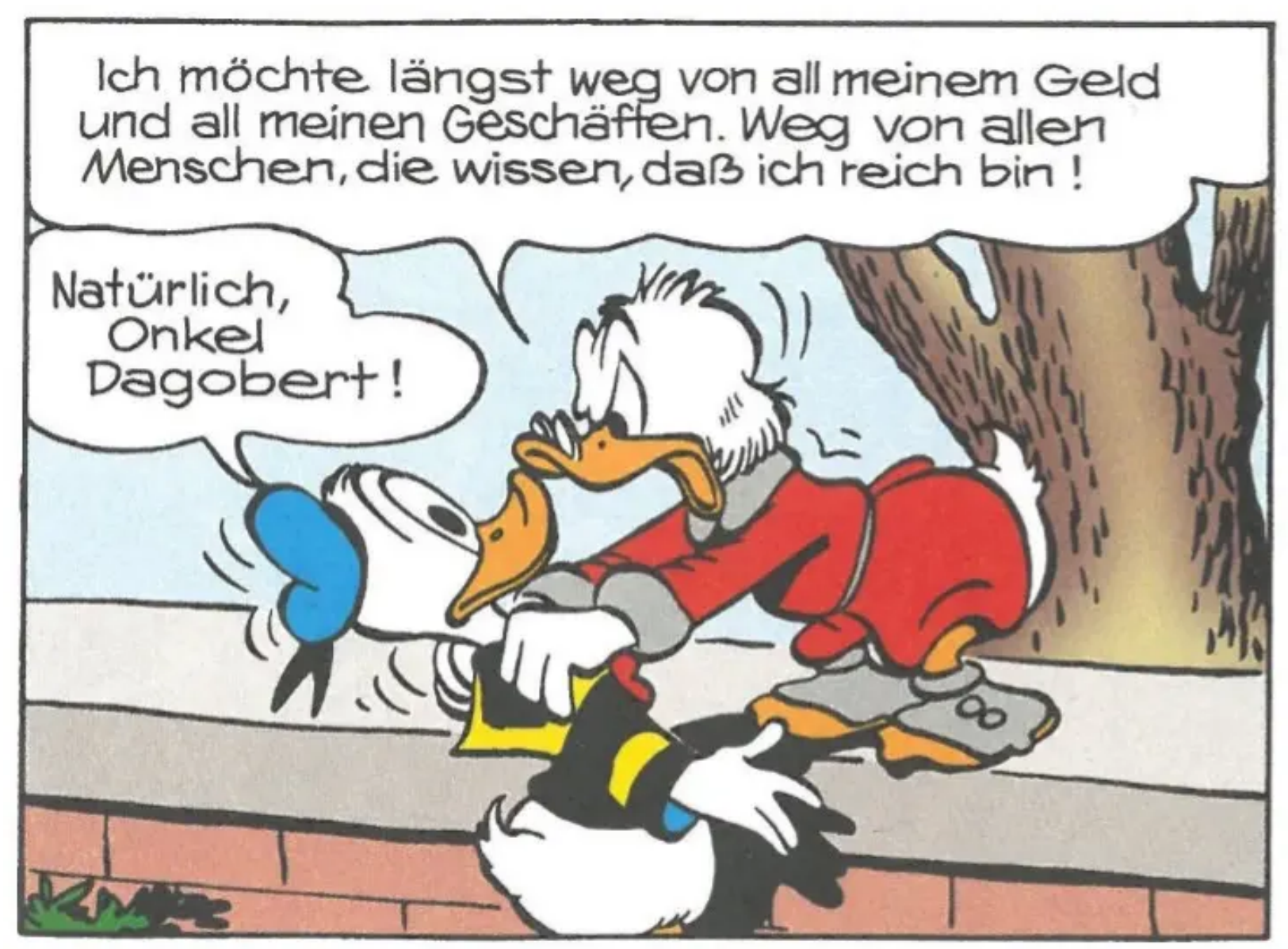

Abb. 5: Der verhängnisvolle Kronenkork (1954), in: Barks Library Special - Onkel Dagobert, Bd. 6, Stuttgart 1998, S. 41.

Verfügt man über das nötige Geld, kann man Inseln auch direkt kaufen. Der Deutsche Farhad Vladi ist Inselmakler und verkauft Inseln auf der ganzen Welt. Lomsjö Island in Schweden mit 0,5 ha kostet noch bescheidene 95.000 Euro. Es befinden sich im Portfolio aber auch Inseln wie Pumpkin Key vor Florida mit 10 ha und 465 qm Wohnfläche für 95 Mio. Dollar oder Kaibu Island im südpazifischen Fidschi, wo man für 155 Mio. Dollar direkt vier Inseln sein Eigen nennen kann. ${ }^{10}$ Die Inselmakler-Branche bemerkte, dass sich seit Ausbruch der Pandemie die Nachfrage nach Privatinseln vervielfacht hatte. Einerseits stieg der Reichtum in der Krise massiv an, andererseits war das Verlangen der Reichen besonders groß, zu verschwinden und sich zu isolieren. Um möglichst rasch wieder in die Welt zurückkehren zu können, wurden deshalb vor allem Inseln mit Flugplätzen bevorzugt. ${ }^{11}$ Schon im antiken Rom war es für Reiche und Mächtige üblich, eine Sommerfrische nicht weiter als eine Tagesreise von der Metropole zu besitzen, um die Geschäfte im antiken Rom regeln zu können. 


\section{Hier werd' ich mich endlich ausruhen können. Hier, wo Geld unbekannt ist und niemand was von mir haben will.}

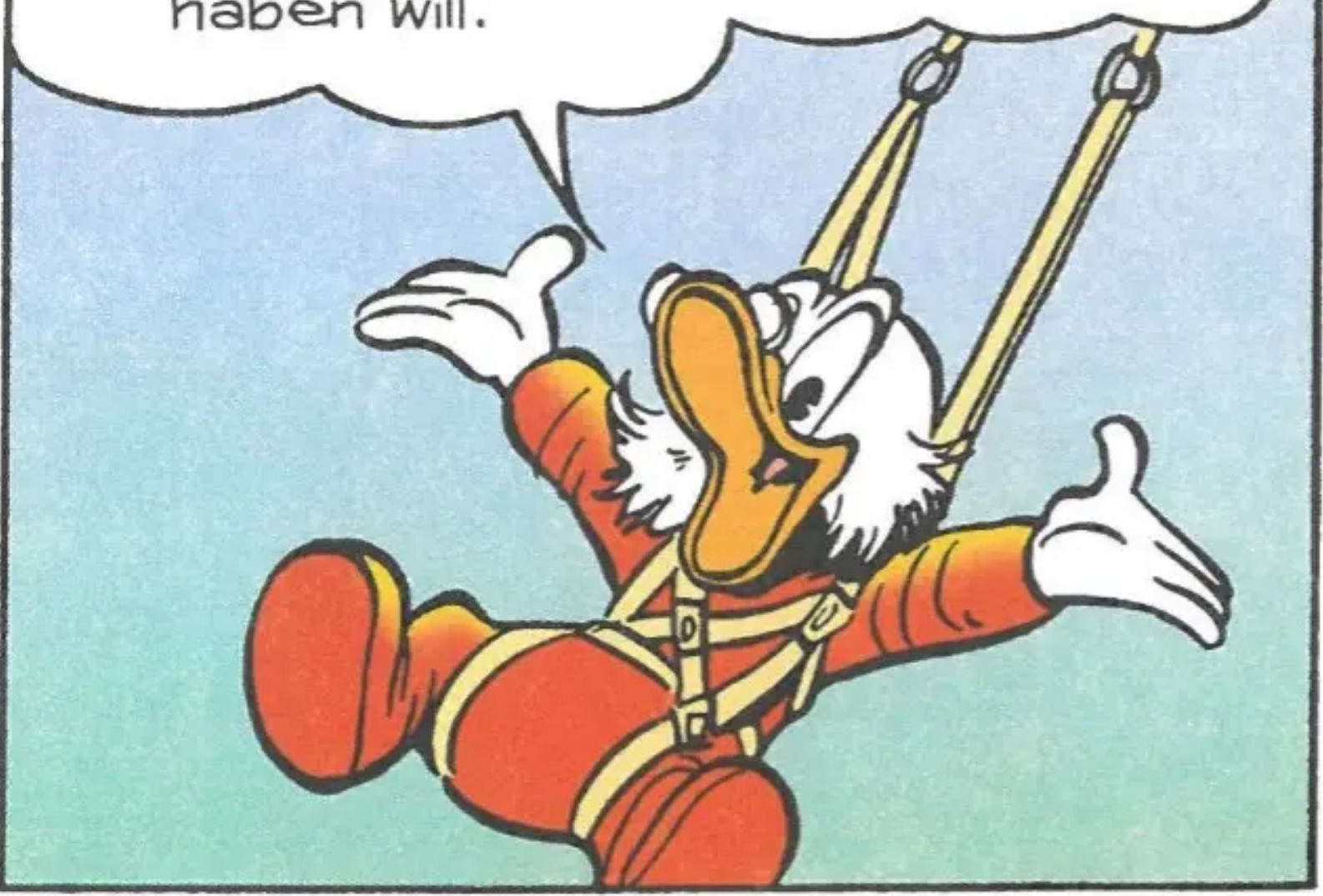

Abb. 6: Der verhängnisvolle Kronenkork (1954), in: Barks Library Special - Onkel Dagobert, Bd. 6, Stuttgart 1998, S. 49.

Auch wenn eine Insel größtmögliche Abgeschiedenheit und damit Schutz vor dem Virus und anderen Gefahren bietet, bleiben Restrisiken. Um in möglichst diskreter Abgeschiedenheit zu bleiben, mieteten die Reichen der Reichen häufig nur Inseln, während die Käufer bei Immobilienmakler Vladi eher die „armen Reichen” waren. ${ }^{12}$ Inseln bieten Schutz vor Viren, sind aber der globalen Klima-Krise ebenso ausgeliefert wie andere Regionen der Erde. Ihre Vulnerabilität ist sogar noch größer, denn die geographische Lage birgt ein deutlich höheres Gefährdungspotential. Als der seit Beginn der Aufzeichnungen stärkste atlantische Hurrikan Irma 2017 die Karibik heimsuchte, wurde auch Necker Island komplett zerstört. Trendsetter Branson, der in seinem Blog noch behauptet hatte, er würde den Hurrikan auf Necker Island aussitzen, entkam nur knapp und konnte unversehrt aus seinem befestigten Weinkeller fliehen, wie die Washington Post berichtete. ${ }^{13}$

Um nicht mehr zu kalkulierenden globalen Katastrophen zu entgehen, scheinen einige Mitglieder der Klasse der ultra-high-net-worth individuals (UHNWIs) weitergehende Pläne zu hegen. Jene wenigen, die absolut sicher sein können, ihr Vermögen nicht zu verlieren, auch wenn die Welt um sie zusammenbricht, planen schon jenseits der Erde. Unbelastet von lästigen Steuern investieren die laut Forbes zwei reichsten Menschen 
der Welt, Jeff Bezos und Elon Musk, Milliardenbeträge in die Raumfahrt. Während Musk von der Menschheit der Zukunft als multiplanetarer Spezies phantasiert, träumt Bezos noch davon, dass Millionen Menschen trabantennah im Weltraum leben und arbeiten könnten, um die Welt vor dem ökologischen Kollaps zu schützen. Das erinnert an Filme wie „Elysium“ von 2013, wo die Superreichen und Privilegierten auf einer Raumstation in Erdnähe leben, während alle anderen Menschen als Heloten auf einem verwüsteten Planeten vegetieren und für sinistere Konzerne des militärisch-industriellen Komplexes arbeiten. Dieser von Hollywood schon seit längerem publikumswirksam in allerlei Blockbustern variierte Plot mag den Amazon-Chef nicht angetrieben haben, aber dennoch ist davon auszugehen, dass es nicht die Werktätigen sind, die in der BezosWelt im Weltraum leben werden. Es könnte ohnehin noch etwas dauern mit dem extraterrestrischen Schritt in die möglichst sichere Distanz. Im Juli 2021 starten die ersten fünf Astronauten, zusätzlich wird ein Platz für einen Touristen versteigert: Für das 10-minütige Kurzstreckenticket wurden 2,3 Millionen Euro geboten.

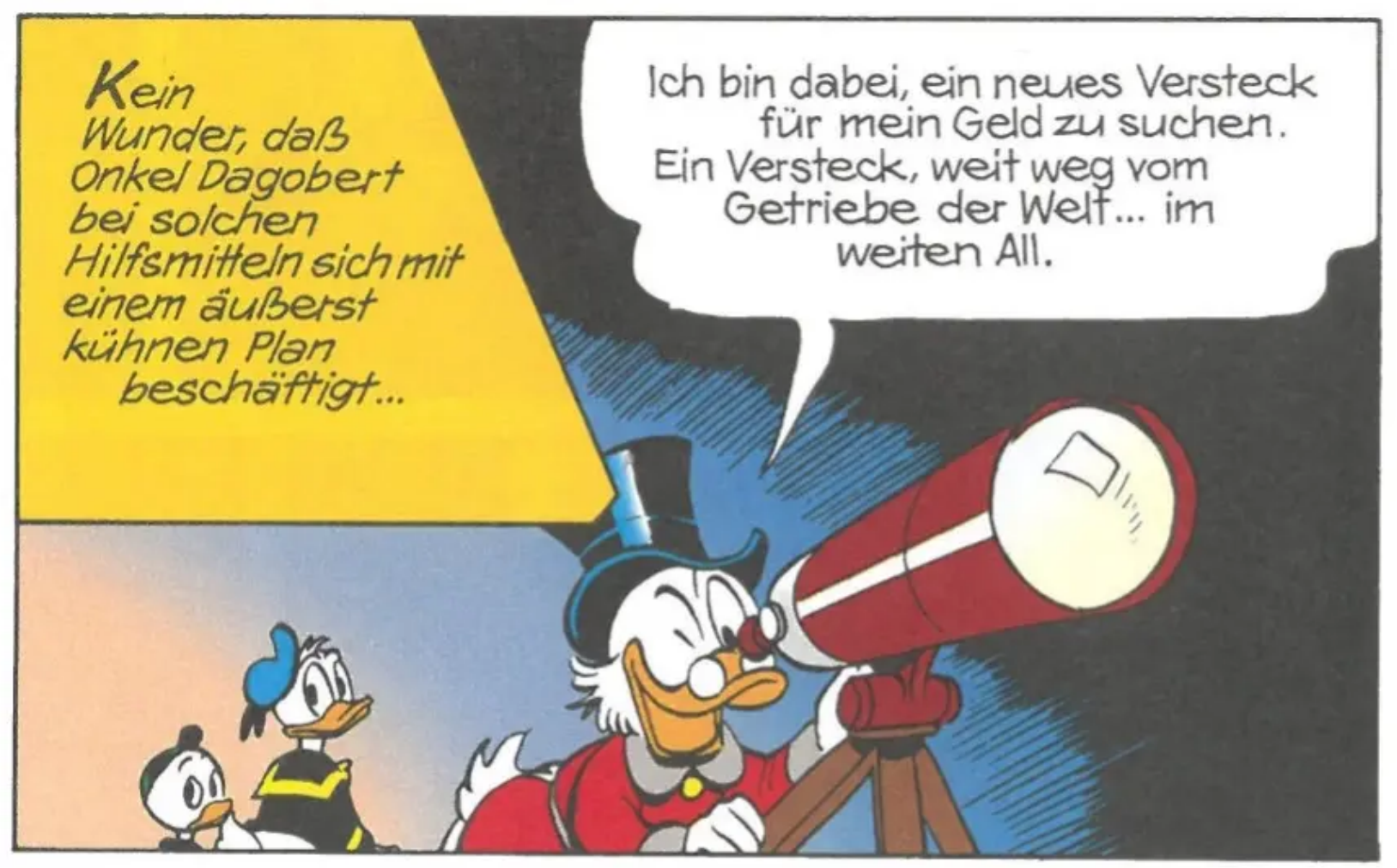

Abb. 7: Die Insel im All (1960), in: Barks Library Special - Onkel Dagobert, Bd. 18, Stuttgart 2000, S. 3.

Angst vor Kriminalität, vor Revolte und Anomie, und zurzeit vor Krankheit und Tod führten immer schon zur Distanzierung der Reichen von ihren Mitmenschen. Im Fall der Corona-Pandemie, wie im Falle jeder Pandemie, ist das Gebot der Abstandswahrung ein wesentliches Mittel zu ihrer Bekämpfung. Aber je geringer das Einkommen und Vermögen von Menschen ist, umso weniger ist es ihnen möglich, genau diesen Empfehlungen nachzukommen. Die gebotenen Regeln zur Distanzierung scheinen Reichen nicht auszureichen; sie gehen auf maximale Distanz, verschwinden in Bunkern und U-Booten oder ziehen sich auf Schiffe und Inseln im Pazifik zurück, um Gebote des social distancing durch größtmögliche physische und geographische Abschottung zu verstärken. Separierung durch Vermögen ist dabei eine historische Konstante. Mit Blick 
auf die USA, China oder Deutschland, wo heute weltweit die meisten Milliardäre leben, wird man Unterschiede in Bezug auf die soziale Ungleichheit, die Traditionen des Reichtums oder die Lebensstile der Wohlhabenden feststellen. Gleichzeitig eint die "globale Klasse“ (Ralf Dahrendorf) „größtmögliche Distanz zu allem Alltäglichen und den Zwängen des Lebens, aber auch zu anderen Klassen und Schichten“, wie der Soziologe Peter Imbusch schon 2009 feststellte. ${ }^{14}$ Es bestehen Zweifel, dass sich daran etwas in den letzten Jahren geändert hat.

\section{References}

1. Boccaccio, Giovanni (1952): Das Dekameron, München: Winkler, S. 17 und 19. Dazu auch Reinhardt, Volker (2021): Die Macht der Seuche. Wie die große Pest die Welt veränderte 1347 -1353, München: Beck, S. 77-88. https://doi.org/10.17104/9783406767319.

2. Reinhardt, S. 81.

3. Kolb, Frank (2002): Rom. Die Geschichte der Stadt in der Antike, 2. Aufl. München: Beck, S. 313ff, 555ff.

4. Alle Abbildungen in diesem Blogtext werden als Bildzitate gemäß § 51 UrhG (deutsches Urheberrechtsgesetz) ausschließlich zur inhaltlichen Erläuterung genutzt.

5. Glasze, Georg (2003): Bewachte Wohnkomplexe und «die europäische Stadt» eine Einführung, in: Geographica Helvetica Jg. 58/Heft 4, S. 286-292. https://doi.org/10.5194/gh-58-286-2003.

6. https://www.swr.de/swr2/wissen/article-swr-12414.html; https://www.deutschlandfunknova.de/beitrag/gated-communities-wohnen-hinterzaeunen.

7. Harlander, Tilman/Kuhn, Gerd (Hrsg.) (2012): Soziale Mischung in der Stadt. Case Studies - Wohnungspolitik in Europa - historische Analyse, Stuttgart: kraemer verlag.

8. Stern 01.01.2018, Managermagazin 31.03.2016.

9. Global Wealth Migration Review 2019 und 2020.

10. www.vladi-private-islands.de.

11. Reif für die Insel, in: FAZ vom 03.02.2021; Social Distancing: Sie bringen sich in Sicherheit, in: ZEIT vom 08.02.2021.

12. ZEIT vom 08.02.2021.

13. Washington Post vom 09.09.2017.

14. Credit Suisse Research Institute, Global wealth report 2020, S. 32; Imbusch, Peter (2009): Unglaubliche Vermögen - Elitärer Reichtum, in: Druyen, Thomas u.a. (Hrsg.): Reichtum und Vermögen: Zur gesellschaftlichen Bedeutung der Reichtums- und Vermögensforschung, Wiesbaden: Verlag für Sozialwissenschaften, S. 226. https://doi.org/10.1007/978-3-531-91752-8_16. 
SUGGESTED CITATION: Flender, Armin: Auf Distanz gehen. Über Angst und Reichtum, in: KWI-BLOG, [https://blog.kulturwissenschaften.de/auf-distanz-gehen/], 28.06.2021

DOI: https://doi.org/10.37189/kwi-blog/20210628-0830 
Dieser Text wird via DuEPublico, dem Dokumenten- und Publikationsserver der Universität Duisburg-Essen, zur Verfügung gestellt. Die hier veröffentlichte Version der E-Publikation kann von einer eventuell ebenfalls veröffentlichten Verlagsversion abweichen.

DOI: $\quad 10.37189 / \mathrm{kwi}-\mathrm{blog} / 20210628-0830$

URN: urn:nbn:de:hbz:464-20210628-110321-0 